Available online: http://openjournal.wdh.ac.id/index.php/edudharma

Edu Dharma Journal: Jurnal Penelitian dan Pengabdian Masyarakat

ISSN (Print) 2597-890 X , ISSN (Online) 2686-6366

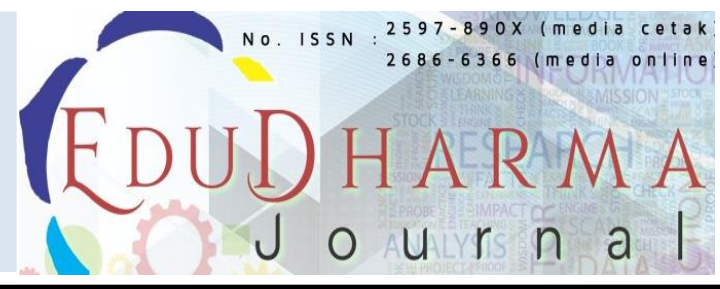

\title{
HUBUNGAN ANTARA AKTIVITAS FISIK, STRES DAN POLA TIDUR DENGAN PREMENSTRUAL SYNDROME (PMS) PADA MAHASISWI PRODI D3 FARMASI STIKES KHARISMA PERSADA
}

Lela Kania Rahsa Puji ${ }^{*}$, Nurwulan Adi Ismaya ${ }^{2}$, Tri Okta Ratnaningtyas ${ }^{3}$, Nur Hasanah ${ }^{4}$, Nada Fitriah ${ }^{5}$

${ }^{1}$ STIKes Kharisma Persada, Jl. Pajajaran No. 1 Kota Tangerang Selatan, Indonesia

\begin{tabular}{|c|c|}
\hline ARTICLE INFORMATION & $A B S T R A C T$ \\
\hline $\begin{array}{l}\text { *Lela Kania Rahsa Puji } \\
\text { Name } \\
\text { E-mail: lilakania@masda.ac.id }\end{array}$ & \multirow{2}{*}{$\begin{array}{l}\text { One of the reproductive health problems that are often experienced by } \\
\text { women and is a major problem in society is menstrual disorders. In } \\
\text { Indonesia } 260 \text { women of childbearing age of 95\% have at least one } \\
\text { Premenstrual syndrom(PMS) symptom, with moderate to severe symptoms } \\
\text { of 3.9\%. From a preliminary study at STIKes Kharisma Persada } \\
\text { Pamulang, } 66.7 \% \text { of women knowledge slight symptoms of premestrual } \\
\text { syndrome (PMS), while } 33.3 \% \text { of women experience moderate to severe } \\
\text { symptoms of premenstrual syndrome (PMS). Objective: from this study is } \\
\text { to analyze physical activity, stress, and sleep patterns with the occurrence } \\
\text { of Premenstrual Syndrome (PMS) in pharmacy students of STIKes } \\
\text { Kharisma Persada Pamulang in 2020. Method: is a quantitative study } \\
\text { with cross sectional. Sample } 97 \text { respondents by simple random sampling. } \\
\text { Data collection using a questionnaire filled out by respondents through } \\
\text { Google form, data analysis chi square test. Results: there is a significant } \\
\text { correlation on each variable (physical activity, stress and sleep patterns) } \\
\text { with the incidence of Premenstrual syndrom(PMS).. }\end{array}$} \\
\hline $\begin{array}{l}\text { Keywords: } \\
\text { Premenstrual Syndrom(PMS)_1 } \\
\text { Physical Activity_2 } \\
\text { Stress_3 } \\
\text { Sleep Patterns_4 }\end{array}$ & \\
\hline \multirow[t]{3}{*}{$\begin{array}{l}\text { Kata Kunci } \\
\text { Premenstrual Syndrom (PMS)_1 } \\
\text { Aktivitas fisik_2 } \\
\text { Stres_3 } \\
\text { Pola tidur_4 }\end{array}$} & $\begin{array}{l}\text { A B S T R A K } \\
\text { Masalah kesehatan reproduksi yang sering dialami oleh wanita dalam } \\
\text { masyarakat adalah gangguan mestruasi. Di Indonesia } 260 \text { wanita usia } \\
\text { subur } 95 \% \text { mengalami minimal satu gejala Premenstrual syndrom(PMS), } \\
\text { antara gejala sedang sampai berat sebanyak } 3,9 \% \text {. Dari studi pendahuluan } \\
\text { di STIKes Kharisma Persada Pamulang didapatkan } 66,7 \% \text { wanita } \\
\text { mengalami gejala ringan dari premestrual syndrome (PMS), sedangkan } \\
33,3 \% \text { wanita mengalami gejala sedang sampai gejala berat dari } \\
\text { premenstrual syndrome (PMS). Tujuan : menganalisis aktivitas fisik, } \\
\text { stres, dan pola tidur terhadap Premenstrual Syndrome (PMS) kepada } \\
\text { mahasiswi PRODI D3 farmasi STIKes Kharisma Persada Pamulang. } \\
\text { Metode kuantitatif dengan cross sectional. Sampel sebesar 97 secara } \\
\text { simple random sampling. Kuesioner diisi oleh responden melalui google } \\
\text { form, analisa data menggunakan uji chi square. Hasil penelitian } \\
\text { didapatkan terdapat hubungan bermakna di setiap variabel aktivitas fisik, } \\
\text { stres dan pola tidur terhadap kejadian Premenstrual syndrom(PMS). }\end{array}$ \\
\hline & This is an open access article under the CC-BY-NC-SA license. \\
\hline & \\
\hline
\end{tabular}




\section{PENDAHULUAN}

Kesehatan reproduksi adalah masalah yang sering dialami oleh wanita dalam masyarakat adalah gangguan menstruasi. Sebelum terjadi menstruasi, gejala perubahan yang sering terjadi adalah dari perubahan fisik dan emosional, gejala tersebut mereda pada siklus menstruasi dimulai. Pada sebagian wanita terjadinya gejala secara terus menerus $24-48$ jam di hari pertama menstruasi dan akan menghilang dalam beberapa hari yang akan datang (Ratikasari, 2015). Gejala tersebut dikenal dengan premenstrual syndrom (PMS). Sebesar 90\% wanita memiliki 1 (satu) hingga beberapa gejala premenstrual syndrom(PMS) selama masa usia subur pada siklus menstruasi (Zaka \& Mahmood, 2012) dan 5-10\% wanita memiliki gejala yang bersifat sedang hingga berat (Ratikasari, 2015).

Menurut Moghadam (2014) dalam (Ratikasari,2015), prevalensi premenstrual syndrom(PMS) seluruh dunia ialah sebesar 47,8\%. Menurut WHO (Word Health Organization), kejadian Premenstrual syndrom(PMS) banyak terjadi pada sebagian negara Asia dibanding dengan negara di Eropa (Mohamadirizi \& Kordi, 2013). Menurut American Collage Obstetricians and Gynecologists (ACOG) di negara Sri Lanka pada 2012, gejala
Premenstrual Syndrom(PMS) terjadi pada remaja putri sebesar $65,7 \%$. Di Iran sekitar 98,2\% prempuan berusia 18-27 tahun memiliki kejadian 1 (satu) gejala Premenstrual Syndrom (PMS) ringan ataupun sedang. Kejadian PMS di negara Brazil terjadi pada populasi perempuan dewasa sebesar 39\%, kejadian Premenstrual Syndrom (PMS) pada perempuan dewasa di Hongkong 17\% pada perempuan dewasa (Basir dkk, 2011dalam (Dia Rianti, 2019).

Di Indonesia 260 orang wanita dewasa memiliki satu gejala Premenstrual Syndrom (PMS) sebanyak 95\%, dengan gejala Premenstrual Syndrom (PMS) sedang sampai berat 3,9\% (Emilia, 2008) dalam (Ilmi \& Utari, 2018). Kejadian Premenstrual Syndrom (PMS) menunjukkan hasil berbeda di sebagian daerah di Indonesia . Jakarta Selatan siswi SMK mengalami Premenstrual Syndrom(PMS) $\quad 45 \% . \quad$ Kejadian Premenstrual Syndrom(PMS) pada mahasiswi Akademik Kebidanan di Kudus didapatkan angka 45,8\%, di Padang siswi SMA mengalami premenstrual syndrom (PMS) sebesar 51,8\%, di Pruworejo siswi SMA yang mengalami kejadian premenstrual syndrom (PMS) sebanyak 24,6\% (Rianti, 2019). Penelitian yang 
dilakukan di Poltekkes Banten didapatkan asil lebih dari $50 \%$ mahasiswa mengalami premenstrual syndrom (PMS) (Hikmah, 2015). Dampak dari premenstrual syndrom (PMS) terjadinya penurunan konsentrasi dalam belajar, absensi kehadiran di kelas mengalami peningkatan serta aktivitas yang menurun (Ramadhani, 2018).

Kejadian premenstrual syndrom (PMS) jenis gejalanya cukup bervariasi dan gejalanya beragam pada setiap individu, penyebab dari gejala Premenstrual Syndrom (PMS) sampai saat ini tidak diketahui secara pasti. Beberapa wanita, mengalami kategori berat, sampai aktivitasnya terganggu (NIH, 2014) dalam (Ratikasari, 2015). Salah satu faktor yang menyebabkan premenstrual syndrom (PMS) adalah aktivitas fisik, tingkat stres, serta pola tidur. Penelitian yang dilakukan Nashruna, (2012) dalam (Estiani \& Nindya, 2018) bahwa wanita yang melakukan olahraga jarang mengalami premenstrual syndrom (PMS) dibandingkan dengan wanita yang tidak atau jarang melakukan olahraga.

Penelitian yang dilakukan oleh Fiskalia (2018) yang berjudul "Hubungan Aktivitas Fisik dengan Premenstrual Syndrome (PMS) pada Remaja Putri di SMAN 8 Kendari Tahun 2018" bahwa terdapat hubungan signifikan antara aktivitas fisik dan Premenstrual Syndrom(PMS) . Menurut Surmiarsih, (2016) dalam (Fiskalia, 2018), menyatakan bahwa faktor kebiasaan olahraga yang kurang bisa memperberat pramenstruasi. Tetapi penelitian yang mendukung hubungan aktivitas fisik dengan Premenstrual Syndrom(PMS) masih sangat sedikit.

Selain itu, faktor yang dapat menyebabkan

Premenstrual Syndrom(PMS) yaitu stres. Penelitian yang dilakukan oleh (Ilmi \& Utari, 2018), mahasiswi Fakultas Kesehatan Masyarakat (FKM) dan Dept. Arsitektur Fakultas Teknik Universitas Indonesia menemukan bahwa setidaknya ada 83,3\% mahasiswi yang memiliki tingkat stres yang tinggi mengalami Premenstrual Syndrom(PMS) dengan gejala berat. Pada mahasiswi Fakultas Fisioterapi Universitas Hasanuudin menemukan sebanyak 28\% mengalami stres ringan, $33 \%$ mengalami stres sedang dan diantaranya mengalami siklus menstruasi tidak normal. Penelitian oleh Aldira (2014) dalam (Ilmi \& Utari, 2018), ini menjelaskan bahwa psikis berpengaruh, psikis penderita bisa diperberat oleh kejadian Premenstrual Syndrom(PMS) .

Faktor selanjutnya yang dapat menyebabkan Premenstrual Syndrom 
(PMS) yaitu pola tidur. Penelitian Lisnawati, (2017) dalam (Ilmi \& Utari, 2018) mengatakan bahwa ada hubungan antara pola tidur dengan Premenstrual Syndrom (PMS) . Dengan kuesioner PSQI, terdapat hubungan Premenstrual Syndrom (PMS) dengan kualitas tidur yang buruk (Cheng dkk, 2013,Karaman dkk, 2012). Baiknya kebiasaan tidur bisa meringankan gejala Premenstrual Syndrom (PMS) . Sekresi hormon di dalam tubuh dipengaruhi oleh baik dan buruknya pola tidur (Shechter dan Boivin, 2010) dalam (Ratikasari, 2015).

Dari penjelasan tersebut peneliti ingin meneliti tentang hubungan gejala Premenstrual Syndrom (PMS) dengan aktivitas fisik, stres, dan pola tidur di STIKes Kharisma Persada Pamulang, yaitu pada mahasiswi Prodi D3 Farmasi angkatan 2017. Dasar pemilihan mahasiswi Farmasi semester akhir pada penelitian ini adalah beban tugas akhir yang dimiliki mahasiswi tingkat akhir mempengaruhi aktivitas fisik, stres, serta pola tidur maka akan mempengaruhi pula kejadian Premenstrual Syndrom(PMS) pada mahasiswi tersebut. Studi pendahuluan dilakukan peneliti pada tanggal 13 April 2020 menunjukkan cukup tingginya presentase gejala Premenstrual Syndrom (PMS) serta bervariasi jenis gejalanya pada setiap individu. Melihat kondisi tersebut maka peneliti ingin mengambil judul hubungan antara aktivitas fisik, stres, dan pola tidur dengan kejadian Premenstrual Syndrom (PMS) pada mahasiswi Prodi D3 Farmasi STIKes Kharisma Persada Pamulang.

\section{METODE}

Desain penelitian ini kuantitatif dengan cross sectional.. Populasi penelitian ini adalah sebanyak 130 mahasiswi dan jumlah sampel sebanyak Subjek 97 mahasiswi Prodi DIII Farmasi STIKes Kharisma Persada angkata 2017. Pengumpulan data pada dengan menggunakan google form dengan simple random sampling. Kuesioner yang digunakan The Shortened Premenstrual Assessment From (SPAF), International Physical Activity Questionnaire (IPAQ), The Kessler Psyhological Distress Scale (K10), dan Pittsburgh Sleep Quality Index (PSQI) yang sudah dinyatakan valid dan reliabel. Analisis data menggunakan analisis univariat untuk mendapatkan gambaran Premenstrual Syndrom(PMS), dan analisis bivariat untuk mencari hubungan antar variabel dengan menggunakan chi-square.

\section{HASIL}


Gambaran Premenstrual syndrome berat sebesar. Diukur menggunakan SPAF (PMS)

Kejadian mahasiswi yang mengalami Premenstrual Syndrom(PMS) 10 gejala. Seluruh gejala Premenstrual sebanyak $63,9 \%$ dengan sedang sampai Syndrom (PMS) yang dirasakan dengan tingkatan berbeda oleh 97 responden (Gambar 1).

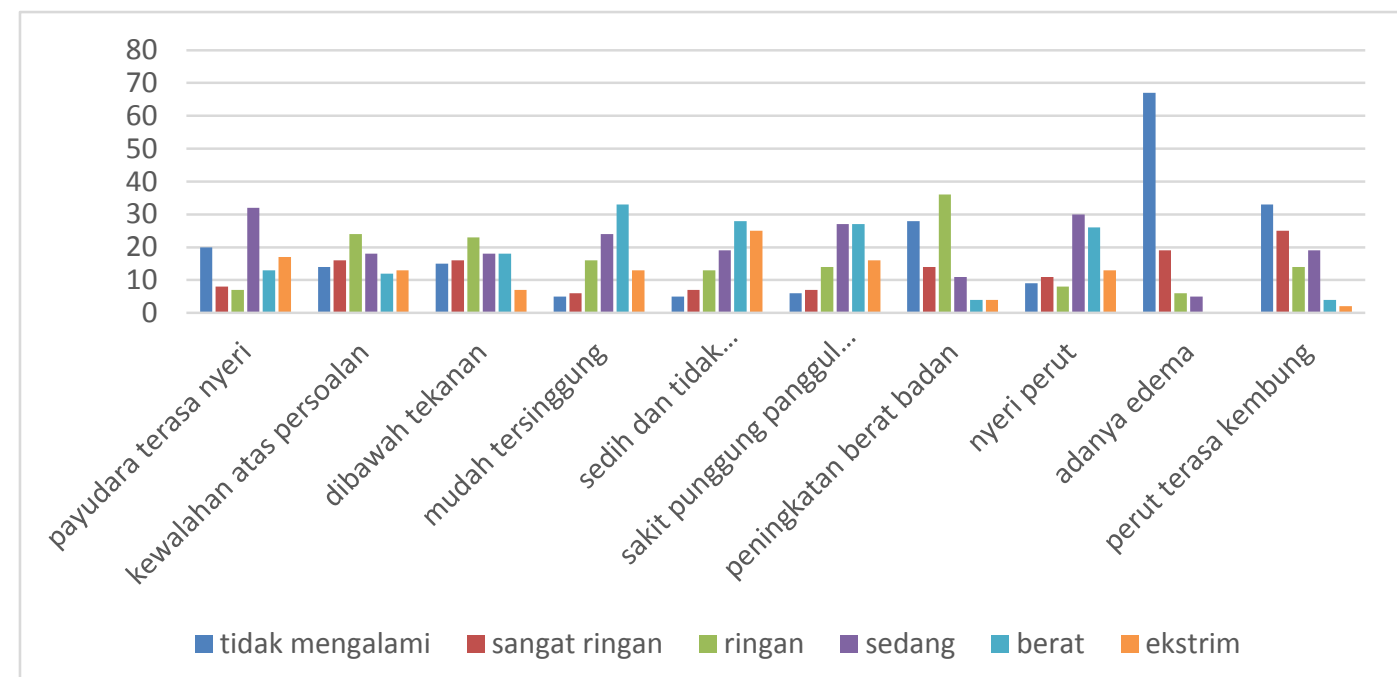

Gambar 1. Gambaran Gejala PMS pada Mahasiswi Prodi DIII Farmasi STIKes Kharisma Persada

Gambar 1 dari sepuluh gejala Premenstrual Syndrom (PMS) yang dirasakan paling berat oleh responden adalah punggung, pinggul dan nyeri sendi $(40,1 \%)$.
3 gejala sedih dan tidak bersemangat $(42,4 \%)$, mudah tersinggung $(40,4 \%)$, sakit

Tabel 1. Proporsi Karakteristik Responden pada Gejala Premenstrual Syndrom(PMS)

\begin{tabular}{|c|c|c|c|c|c|c|c|c|}
\hline \multirow[t]{2}{*}{ Variabel } & \multirow[t]{2}{*}{ Kategori } & \multirow[t]{2}{*}{$\mathrm{n}$} & \multirow[t]{2}{*}{$\%$} & \multicolumn{2}{|c|}{$\begin{array}{l}\text { Gejala sedang- } \\
\text { gejala berat }\end{array}$} & \multicolumn{2}{|c|}{$\begin{array}{l}\text { Tidak ada gejala - } \\
\text { gejala ringan }\end{array}$} & \multirow[t]{2}{*}{ p-value } \\
\hline & & & & $\mathrm{n}$ & $\%$ & $\mathrm{n}$ & $\%$ & \\
\hline \multirow[t]{3}{*}{ Aktivitas fisik } & Ringan & 52 & 53,6 & 39 & 75,0 & 13 & 25,0 & \multirow{3}{*}{0,019} \\
\hline & Sedang & 20 & 20,6 & 8 & 40,0 & 12 & 60,0 & \\
\hline & Berat & 25 & 25,8 & 15 & 60,0 & 10 & 40,0 & \\
\hline \multirow[t]{4}{*}{ Stres } & Tinggi & 45 & 46,4 & 39 & 86,7 & 6 & 13,3 & \multirow{4}{*}{0,001} \\
\hline & Sedang & 17 & 17,5 & 10 & 58,8 & 7 & 41,2 & \\
\hline & Rendah & 21 & 21,6 & 10 & 47,6 & 11 & 52,4 & \\
\hline & $\begin{array}{l}\text { Tidak } \\
\text { mengalami }\end{array}$ & 14 & 14,4 & 39 & 86,7 & 6 & 13,3 & \\
\hline \multirow[t]{2}{*}{ Pola tidur } & Buruk & 89 & 91,8 & 62 & 69,7 & 27 & 30,3 & \multirow{2}{*}{0,001} \\
\hline & Baik & 8 & 8,2 & 0 & 0,0 & 8 & 100,0 & \\
\hline
\end{tabular}

Sumber : Data Primer, tahun 2020

Aktivitas fisik dikelompokan dalam

3 kelompok, ringan, sedang, dan berat. 
Tingkat stres dikelompokan 4 kelompok, tinggi $(\geq 30)$, rendah (25-29), sedang (2024), tidak stres $(<20)$. Tabel 1 sebesar $46,4 \%$ sebagian besar responden stres tinggi,. Pola tidur dikelompokan 2 kelompok buruk (> 5), dan baik $(\leq 5)$. Tabel 1 pola tidur yang dimiliki oleh responden sebesar $89 \%$ adalah pola tidur buruk. Tabel 1 menunjukkan pola tidur memiliki hubungan dengan terjadinya gejala Premenstrual Syndrom(PMS) $(p=0,019)$ sebesar $69,7 \%$. Stres dengan gejala Premenstrual Syndrom(PMS) memiliki hubungan dengan nilai $\alpha<0,5$ $(p=0,001)$ sebesar $86,7 \%$. Dan ada hubungan aktifitas fisik dengan gejala Premenstrual Syndrom (PMS) sebesar $75,0 \%$

\section{PEMBAHASAN}

Aktivitas fisik berhubungan dengan gejala Premenstrual Syndrom(PMS) . Sejalan dengan penelitian (Wijayanti, 2015), (Pertiwi, 2016), (Kroll-Desrosiers et al., 2017). Peranan faktor gaya hidup, aktivitas fisik teratur dapat mengurangi sindroma premenstruasi. Olahraga yang teratur dapat meningkatkan produksi endorphin, sehingga bisa membuat perasaan jadi santai dan tenang. Peran hormon Endorphin adalah mengatur hormon endogen. Premenstrual
Syndrom(PMS) biasanya terjadi karena kelebihan estrogen. Olahraga teratur berkontribusi meningkatkan hormon endorphin. Wanita yang PMS karena kelebihan hormon estrogen, dengan meningkatkan hormon endorphin dapat mencegah kelebihan hormon estrogen. Kurangnya melakukan aktivitas olahraga akan memiliki hormon estrogen lebih tinggi. Ini menyebabkan peningkatan resiko Premenstrual Syndrom(PMS) pada wanita yang tidak teratur melakukan aktivitas fisik.

Penelitian ini menunjukkan bahwa tingkat stres yang tinggi akan berhubungan gejala Premenstrual Syndrom (PMS) . Sejalan dengan penelitian yang dilakukan oleh Prima (2015), Putri (2017), Irma, (2020). Menunjukkan bahwa psikis sangat berpengaruh, kejadian psikis penderita dapat memperberat Premenstrual Syndrom (PMS) . Teori yang dikatakan oleh Nasution (2007) dalam (Ulum, 2016) stres adalah adanya tuntunan internal atau eksternal yang bisa membahayakan, tidak terkendali dan bisa melebihi kemampuan individu, individu bereaksi melakukan penyesuaian diri pada situasi. Sesuai dengan teori Rahajeng (2006) dalam (Irma, 2020) respon psikologis dan fisiologis terhadap stressor adalah salah satu bentuk ketegangan seperti mudah marah, tertekan, 
tingkat kecemasan, mudah tersingung, mengalami frustasi. Stres mengakibatkan penyimpangan pengeluaran beta-endorphin yang menimbulkan gejala pramenstruasi. Keluhan pada psikis seperti mengalami depresi, lebih sensitif, mudah emosi, tidur tidak nyenyak, mudah lelah, cepatnya terjadi perubahan suasana hati (Pratiwi dan Haryanto, 2019; Irma, 2020). Beberapa penelitian menyebutkan bahwa pola tidur akan mempengaruhi gejala Premenstrual Syndrom(PMS) - pada uji statistik terdapat korelasi antara kebiasaan tidur dengan gejala Premenstrual Syndrom (PMS). Hal ini sejalan dengan penelitian (Ratikasari, 2015), (Cheng et al., 2013), (Ilmi \& Utari, 2018). Semakin buruk kualitas tidurnya, semakin besar keparahan PMS. Tidur yang cukup dapat memulihkan kondisi tubuh secara fisiologis ataupun psikologis. Tidur adalah kebutuhan manusia, pada saat tidur proses pemulihan dilakukan oleh tubuh dan kembali pada kondisi prima. Pola tidur baik dapat meringankan Premenstrual Syndrom(PMS) dikarenakan hormon didalam tubuh dipengaruhi oleh baik dan buruknya pola tidur (Boivin \& Shechter, 2010)

\section{KESIMPULAN}

Penelitian ini untuk mengetahui korelasi aktivitas fisik, stres, dan kebiasaan tidur terhadap kejadian Premenstrual Syndrom(PMS) pada mahasiswi Prodi DIII Farmasi STIKes Kharisma Persada. Sebagian besar mahasiswi mengalami gejala berat hingga gejala sedang dari Premenstrual Syndrom(PMS) yang paling banyak oleh mahasiswi Prodi DIII Farmasi tidak bersemangat dan sedih.

\section{DAFTAR PUSTAKA}

Boivin, D. B., \& Shechter, A. 2010. Sleep, hormones, and circadian rhythms throughout the menstrual cycle in healthy women and women with premenstrual dysphoric disorder. International Journal of Endocrinology.https://doi.org/10.1155 /2010/259345

Cheng, S. H., Shih, C. C., Yang, Y. K., Chen, K. T., Chang, Y. H., \& Yang, Y. C. 2013. Factors associated with premenstrual syndrome - A survey of new female university students. Kaohsiung Journal of Medical Sciences, 29(2), 100-105. https://doi.org/10.1016/j.kjms.2012.0 8.017

Dia Rianti. 2019. Jurnal midwifery. Akademi Bidan, 1(2), 68-78.

Estiani, K., \& Nindya, T. S. 2018. Hubungan Status Gizi, Asupan Magnesium Dengan Kejadian Premenstrual Syndrome (PMS) Remaja Putri. Media Gizi Indonesia, 13(1), 20. https://doi.org/10.20473/mgi.v13i1.20 $-26$

Ilmi, A. F., \& Utari, D. M. 2018. Faktor Dominan Premenstrual Syndrome Mahasiswi (Studi Pada Mahasiswi 
Fakultas Kesehatan Masyarakat Dan Departemen Arsitektur Fakultas Teknik, Universitas Indonesia). Media Gizi Mikro Indonesia, 10(1), 39-50.

https://doi.org/10.22435/mgmi.v10i1. 1062

Irma, F. 2020. Hubungan Tingkat Stres Dengan Sindrom Pramenstruasi Pada Siswi Sma Irma Fidora 1), Nur Intan Yuliani 2) Universitas Muhammadiyah Sumatera Barat. XIV(01), 70-74.

Kroll-Desrosiers, A. R., Ronnenberg, A. G., Zagarins, S. E., Houghton, S. C., Takashima-Uebelhoer, B. B., \& Bertone-Johnson, E. R. 2017. Recreational physical activity and premenstrual syndrome in young adult women: A cross-sectional study. PLoS ONE, 12(1), 1-13. https://doi.org/10.1371/journal.pone.0 169728

Mohamadirizi, S., \& Kordi, M. 2013. Association between menstruation signs, anxiety, depression, stress in school girls in Mashhad in 20112012. Iranian Journal of Nursing and Midwifery Research.

Pratiwi, R.D and Haryanto, S., 2019. Pengaruh Relaksasi Otot Progresif Terhadap Tingkat Stress Pada Mahasiswa S1 Semester Akhir Fakultas Ekonomi Jurusan Management Keuangan Universitas Pamulang. Jurnal penelitian dan pengabdian masyarakat, 3(1), pp.115.

Pertiwi, C. 2016. Hubungan Aktivitas Olahraga dengan Kejadian Sindrom Pramenstruasi pada Remaja di SMAN 4 Jakarta. Jurnal Ners Dan Kebidanan (Journal of Ners and Midwifery),
(April), 120.

Prima. 2015. Faktor - Faktor Yang Berhubungan Dengan Pre Menstrual Syndrome Pada Mahasiswa TK II Semester III Jurusan Kebidanan Poltekkes Kemenkes Mataram Syajaratuddur Faiqah, Rita Sopiatun. I(2), 1486-1494.

Putri, K. M. 2017. Hubungan Aktifitas Fisik, Depresi dengan Kejadian Sindrom Pra Menstruasi. JI-KES (Jurnal Ilmu Kesehatan), 1(1), 18-24. https://doi.org/10.33006/jikes.v1i1.55

Ramadhani, M. 2018. Premenstrual syndrome (PREMENSTRUAL SYNDROM (PMS). Encyclopedia of Endocrine Diseases, 7(1), 432-435. https://doi.org/10.1016/B978-0-12801238-3.03915-5

Ratikasari, I. 2015. Faktor-Faktor yang Berhubungan dengan Kejadian Sindrom Pramenstruasi (PMS) Siswi SMA 112 Jakarta Tahun 2015.

Risky Fiskalia. 2018. Hubungan Aktivitas Fisik Dengan Premenstrual Syndrome (PREMENSTRUAL SYNDROM (PMS)) Remaja Putri Di Sman 8 Kendari. Politeknik Kesehatan Kendari.

Wijayanti, Y. T. 2015. Analisis faktor yang berhubungan dengan kejadian premenstrual syndroma remaja putri. Jurnal Kesehatan Metro Sai Wawai, Vol. 8, pp. 1-7.

Zaka, M., \& Mahmood, K. T. 2012. Premenstrual syndrome- A review. Journal of Pharmaceutical Sciences and Research. 